\title{
FIELD STUDY ON SS DISCHARGE FROM COMBINED SEWER SYSTEM OF HIGHLY URBANIZED AREA
}

\author{
TADAHARU ISHIKAWA ${ }^{1}$, SHIN MIURA ${ }^{2} \&$ REIKO YAMAMOTO ${ }^{2}$ \\ ${ }^{1}$ Tokyo Institute of Technology, Tokyo, Japan. \\ ${ }^{2}$ CTI Engineering Co., Ltd., Tokyo, Japan.
}

\begin{abstract}
The sewage coverage rate in Tokyo Ward has reached $100 \%$, however, $80 \%$ of this coverage is combined sewer systems that were built before 1980. Consequently, large quantities of organic pollutants are discharged from the rainwater outlets into rivers during heavy rainfalls. The organic pollutants accumulate in downstream brackish-water regions, and water quality problems such as floating scum, foul odors, and cloudy water arise as a result of chemical changes associated with bottom water becoming anaerobic. In this study, the suspended solid (SS) runoff characteristics were investigated in the Nomi River drainage basin in which a combined sewer system handles $100 \%$. The overflow water depth and SS were measured at the weir in one rainwater outlet during two storm events, and the parameters for MIKE URBAN software that calculates sewer runoff were adjusted in the ranges recommended by the manual so that the observation results could be reproduced well. Next, the model was applied to the 38 outlets in the entire catchment of the Nomi River, and the estimated discharges were input into a one-dimensional unsteady river flow model. Observational results of water level and turbidity measurements within the river channel were satisfactorily reproduced by the calculation.
\end{abstract}

Keywords: combined sewer system, rainfall runoff, SS discharge, urban catchment

\section{INTRODUCTION}

In Tokyo Ward, there are eight river systems that drain the urban area on a diluvial plateau. The rivers flow down the slope of the plateau, and subsequently pass through a nearly horizontal brackish-water region of river channels before entering Tokyo Bay. Since the sewage coverage rate for the catchment basin has reached $100 \%$, the water runoff in clear weather is comparatively clean. However, because approximately $80 \%$ of the sewers are combined sewer systems constructed before 1980 [1], during heavy rainfall, water containing high concentrations of suspended solids (SS) overtops the weirs of rainwater outlets and flows into rivers. The SS tend to accumulate as a fine sediment layer in the transition from the sloping plateau to the horizontal gradient reach [2].

After flooding, density stratification is developed in the horizontal sections due to the seawater intrusion under the river water, and the bottom water layers become oxygen deficient. Consequently, organic pollutants contained in the accumulated fine sediment are reduced to generate anaerobic gases, giving rise to water quality problems such as floating scum, foul odors, and cloudy water [2-5]. It is therefore necessary to quantitatively estimate the transport process of SS from combined sewer systems to river channels in order to develop techniques to control the water quality.

In this study, a field investigation was performed to clarify SS inflows from the combined sewer system and the downward flow process in the catchment basin of Nomi River located in southern Tokyo. (1) An automated measuring instrument was installed at the weir in one rainwater outlet to measure the overflow water depth and SS. (2) A runoff model for the rainwater outfall was built by adding an outlet weir module to the MIKE URBAN software [6], and the model parameters were adjusted to reproduce the results of field observations for two storm events. (3) The model was applied to 38 rainwater outlets located in the entire 
catchment basin to estimate the time-distance variation of SS load on the river. (4) These estimates were input into a MIKE11 [7], 1-D unsteady flow model, to calculate the flow rate and SS transport rate in the river channel. (5) The computation results were compared with the results of separately conducted measurements of river water level and turbidity to verify the model performance.

\section{STUDY SITE}

Figure 1 shows the Nomi River catchment basin. The main channel length is $14.4 \mathrm{~km}$, and the catchment basin area is $17.7 \mathrm{~km}^{2}$. The population in the catchment area is approximately 230,000 (population density: ca. 15,000 people $/ \mathrm{km}^{2}$ ), and the percentage urbanization is greater than $96 \%$ [8]. The sewage coverage rate is $100 \%$, and the entire system is a combined sewer system developed from the 1960 s to the 1970s. Approximately $5 \mathrm{~km}$ of the river upstream indicated by sky-blue dotted line from Kodai-Bridge $(9.5 \mathrm{KP}$, where KP is the distance from the mouth of the river) is comprised of culverts, and the $4 \mathrm{~km}$ from Kodai-Bridge to Yogenji-Bridge (5.5 KP; sky-blue solid line) is a concrete-lined open channel. Downstream from Yogenji-Bridge (solid dark-blue line), the river channel is characterized as a brackish-water region with an almost horizontal slope. Because the drainage water from the area close to the downstream river channel is all sent directly to a sewage treatment plant near the coast, this river segment receives no drainage water.

There are 38 rainwater outlets in the reaches of the Nomi River, and runoff enters the river when the water level on the upstream side exceeds a concrete weir built in the outlet. Dimensions of the structures were determined from the design sewage flow rate and the design high-water level at each outlet location. The flow rate for river channel design is determined from a runoff calculation using the rational method (target rainfall intensity: $100 \mathrm{~mm} / \mathrm{h}$ ). The design flow rate at the Yogenji-Bridge is $120 \mathrm{~m}^{3} / \mathrm{s}$ [8].

\section{METHODOLOGY}

\subsection{Field observations}

Sewer outlet observation was carried out at the site indicated by $A$ in Fig. 1. On the upstream side of the overflow weir, a pressure-type water level gauge was installed to measure the

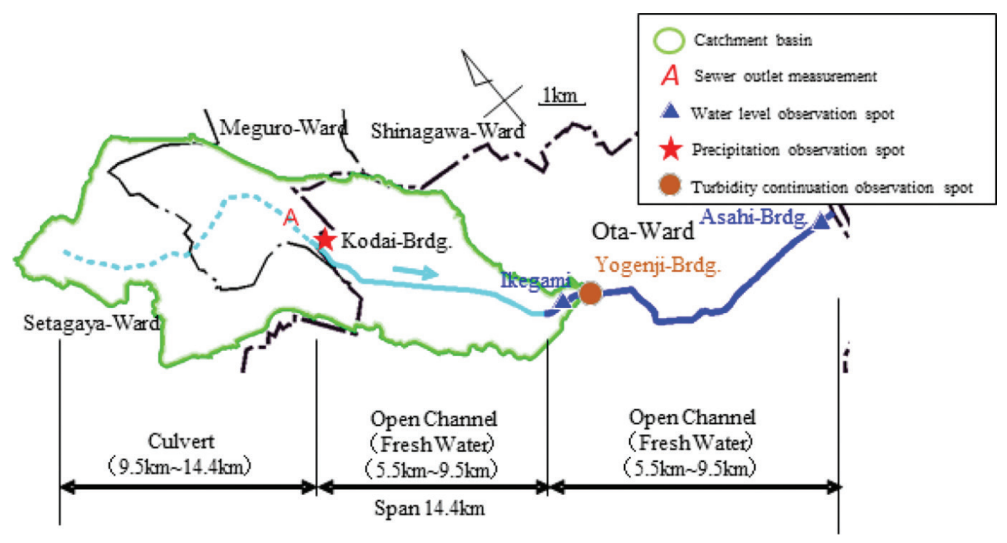

Figure 1: Nomi River catchment basin. 
overflow water depth, and an automatic water sampler was installed to take water during flooding. SS concentration of each water sample was determined in laboratory later. The measurement period was from 5 September to 23 October 2015.

A turbidity meter was installed immediately downstream of Yogenji-Brdg. The installation period was the same as that for the observations at the sewer outlet described above, but because the instrument was out of order to 11 September, effective observations was from 12 September. Measured turbidity was converted to SS using the correlation between SS and turbidity obtained from the laboratory test on the sediment sampled at the sewer outlet. Figure 2 presents the correlation between $\mathrm{SS}$ values $(\mathrm{mg} / \mathrm{L})$ and turbidity values $\left(\mathrm{C}_{\text {Turb }}\right.$, NTU), in which the solid line shows the following equation obtained by the least squares method.

$$
S S=1.4 C_{\text {Turb }}
$$

Rainfall records at the Kodai-Bridge observatory, indicated by red asterisk in Fig. 1, were used for runoff calculation. Because the rain gauge is a tipping bucket type, the output consists of discrete pulse data when the rainfall amount is small. Hence, the continuous graph of rainfall intensity was obtained by taking moving average of the cumulative rainfall graph with 30 minutes for averaging.

The record of water surface level obtained at Ikegami ( $5.6 \mathrm{KP})$, indicated by a blue triangle in Fig. 1, by a water gauge installed at Tokyo Metropolitan Government was used for verification of runoff calculation. However, because the Ikegami water gauge did not respond to the water level lower than A.P. $+1.9 \mathrm{~m}$ due to the reason of facility construction, the record from the water gauge installed at Asahi-Bridge (1.0 KP) near the river mouth was used instead, since the water surface downstream from Ikegami is nearly horizontal when the flow rate is low.

\subsection{Sewer runoff model}

The sewer collection module for combined systems included in MIKE URBAN software [6] was used by adding a module for sewer outlet. Figure 3(a) shows the structure of sewer outlet

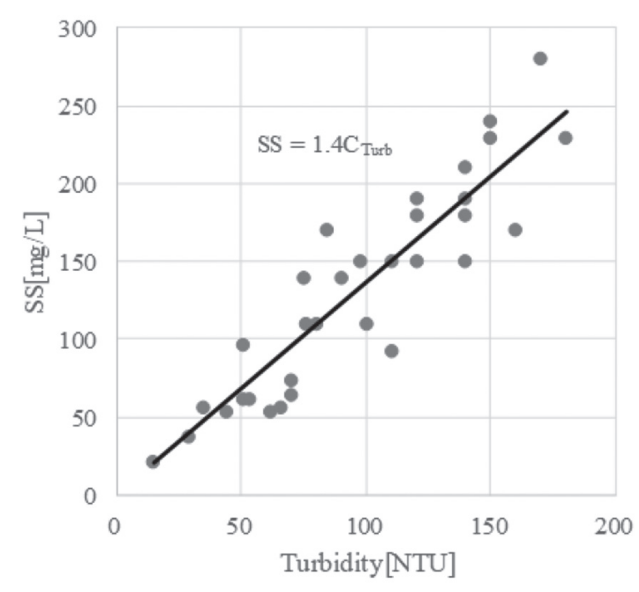

Figure 2: Correlation between SS and turbidity. 
(a) Structure of sewer outlet

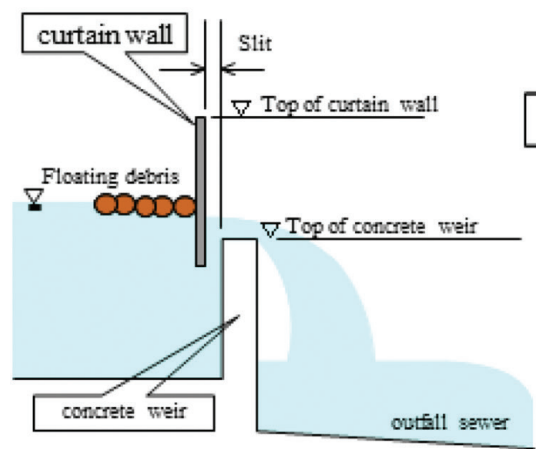

(b) Model of sewer outlet

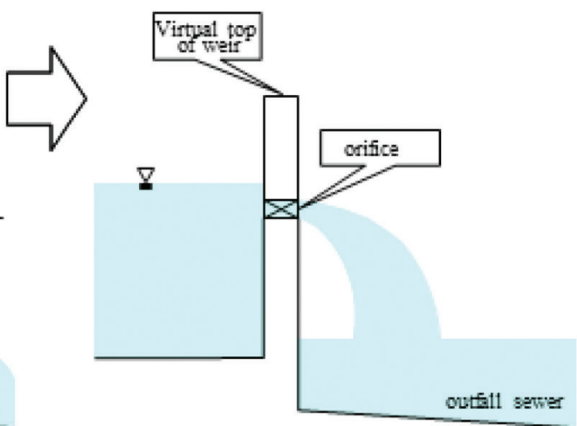

Figure 3: Modeling image of rainwater outlet.

schematically: There is a curtain wall on the upstream-side of the concrete weir to remove floating debris, with a slit to discharge excess water over the weir for comparatively low water stage. At high water stage, sewer water overtops the curtain wall. The structure was modeled as a single weir with an orifice having a pass-through cross-section equivalent to the slit as shown in Fig. 3(b).

Based on the Sewerage Mapping and Information System [9], a drainage channel map was prepared as in Fig. 4, considering pipes and culverts with an inner diameter $\geq 600 \mathrm{~mm}$ and

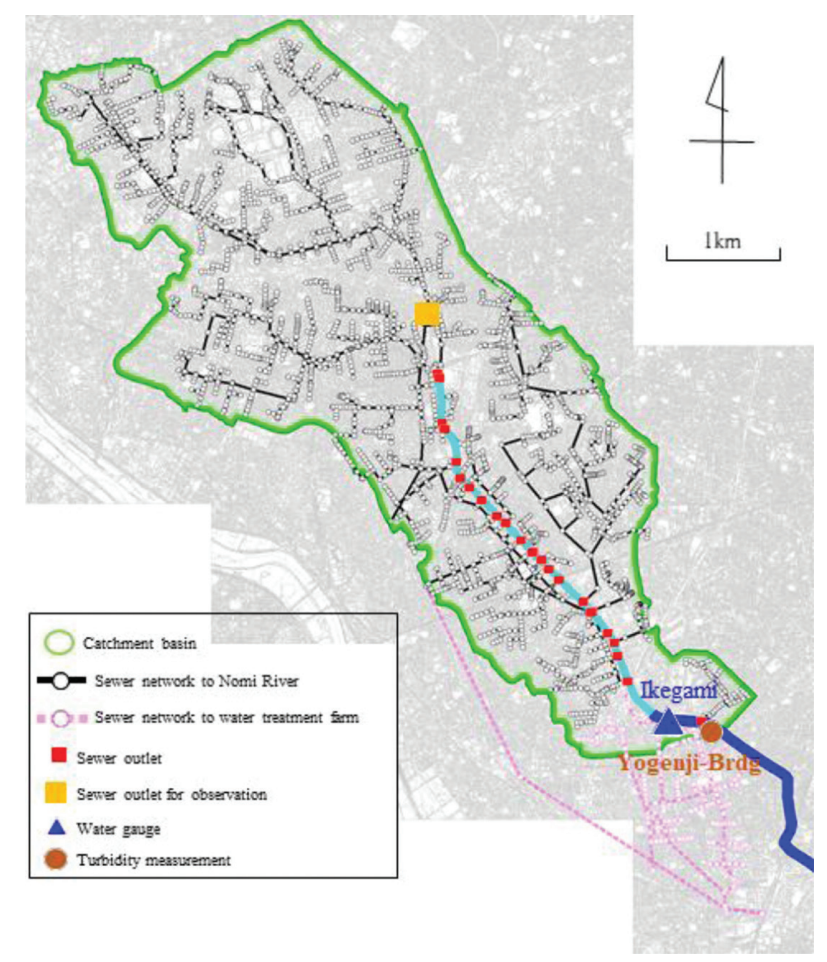

Figure 4: Drainage system of Nomi River catchment basin 
manholes to access them. Sewage in the areas marked in pale pink is sent directly to a sewage treatment plant on the coast, and, therefore, was excluded from calculations. The sewage system flowing into the Nomi River comprised 3,588 pipes and culverts, and had 3,593 manholes with a catchment area for each manhole of 0.1 to $12 \mathrm{ha}$. In addition, the arrival time for sewer outlet estimated by the time-area method was less than $7 \mathrm{~min}$, which was sufficiently shorter than the rainfall duration.

The model parameters contained in MIKE URBAN were set so that the calculated values would come as close as possible to the data obtained in the observations described in 3-1, considering the recommended ranges listed in the manual. Flow rate and SS flux time series were calculated for each of the 38 sewer outlets under the precipitation conditions recorded during the two storms.

\subsection{River flow model}

Using software MIKE11 [7], flow rate and SS flux in the unsteady flows was calculated during the two storm events by inputting the inflow hydrographs at the sewer outlets. Runoff to the upstream culvert section (sky-blue dotted line shown in Fig. 1) was assumed to the upstream end section of open channel (Kodai-Bridge), and the runoff to the middle river reach from Kodai-Bridge to Yogenji-Bridge was given at each sewer outlet section. The downstream-end water level was given as the water-level record obtained by a water gauge at Asahi-Bridge station.

In the SS transport calculation, no-sediment deposition was assumed in the concrete-lined channel upstream from Yogenji-Bridge, because sediment collected in the Nomi River sewerage trunk line was sufficiently fine (a mixture of silt and fine sand).

\section{RESULTS AND DISCUSSIONS}

\subsection{Discharge from the sewer outlet}

During the study period, flooding occurred on September 17 and 25, and these events are referred to as Flood A and Flood B below. The total amount of rainfall for each flood was 64 $\mathrm{mm}$ and $33 \mathrm{~mm}$, respectively. The measured water depth and SS at the outlet weir are indicated by $\mathrm{O}$ and $\boldsymbol{\Delta}$ for Flood A in Figs. $5 \mathrm{a}$ and b, and are shown in the same manner for Flood (B) in Figs. 6a and b. The bar graphs in the top of the figures show the rainfall intensity observed at Kodai-Bridge station. The horizontal lines in the water depth graphs indicate the weir height.

The solid lines in the figures show the calculation results obtained by MIKE URBAN. The model parameters were optimized so that the trial calculation results agreed as much as possible with the observation results. The final parameter values are shown in Table 1. The numbers in column (3) are general value ranges or initially assumed values indicated in the manual, and those in column (4) are the values ultimately determined in this research.

In Flood (A), overflow started at about 4:30 and continued for about twelve hours with variation corresponding to rainfall. The calculation results closely described the observed results. High SS concentration was observed after 0:00 about three hours before the overflow took place, and calculation explained the time and the value of peak very well. In Flood (B), on the other hand, high SS concentration appeared during the first overflow from the outlet, which means that a large amount of SS was discharged to the river. Calculation results accorded with observation very well. 
Table 1: Model parameters.

(1) item

runoff reduction factor $\mathrm{f}$
initial loss $R_{l}$
concentration time $t_{r}$

.

흠

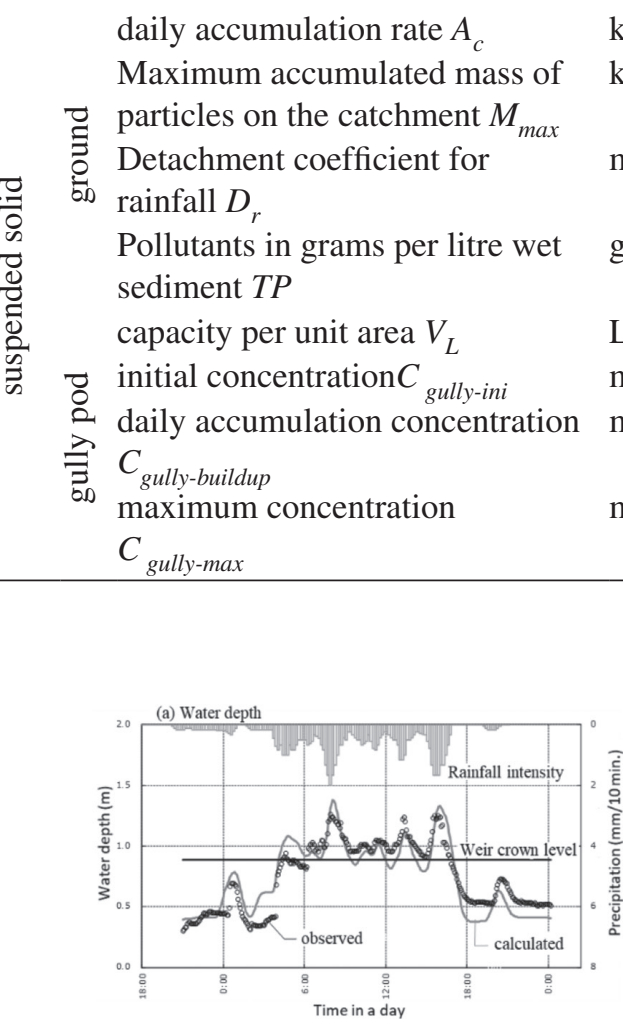

(2) unit

(3) General value (4) setting (a initial value) value

$\begin{array}{lll}- & 0.05 \sim 1.0 & 0.76\end{array}$

$\mathrm{mm}$

$0 \sim 6$

$5 \sim 10$

$4 \quad 1$

$\min$

$0.010 \sim 0.025$

7

$\mathrm{m}^{-1 / 3} \mathrm{~s}$

(50)

(500)

$30 \quad 5$

$500 \quad 1000$

$\mathrm{m} /$ hour

(0.001)

0.003

$\mathrm{g} / \mathrm{L}$

(50)

$100 \quad 100$

L/ha (2300)

1500

$\mathrm{mg} / \mathrm{L}$

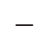

$100 \quad 0$

$50 \quad 100$

$\mathrm{mg} / \mathrm{L}$

1200

Figure 5: Water level and SS in the outlet (Storm A: September 16-17)
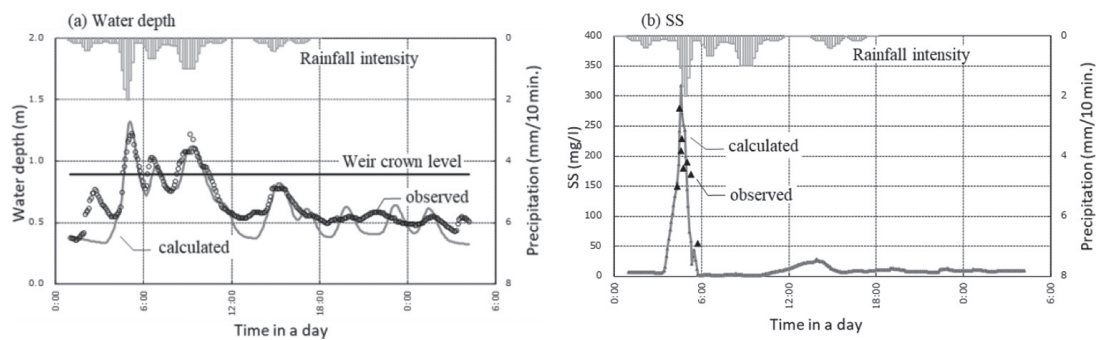

Fig. 6 Water level and SS in the outlet (Storm B: September 25-26) 
4.2 River water level and turbidity.

For Flood-A, calculation result for water level at Ikegami station is compared with observation result in Fig. 7(a). Figure 7(b) shows the comparison for SS at Yogenji-Bridge, where SS data were obtained from turbidity data using Eq. (1). Calculation of water level showed good agreement with observation, although there was no observation for the water level lower than 1.9 A.P.m due to the reason of facility construction, as mentioned earlier. On the other hand, SS calculation well described the time and the level of two peaks, but did not show the long tail after the second peak, the reason of which was not clear.

The results for Flood B are plotted in the same manner in Figs. 8a and b. Calculated water level showed three peaks while the first two ones were not observed probably because they were a little lower than the detection limit, 1.9 A.P.m. On the other hand, SS calculation well described the time and the level of SS peak which corresponded to the first water level peak. The level of SS concentration was much higher than that observed during Flood-A because the high SS water overtopped the outlet weir at the first runoff peak, as explained in Fig. 6. This fact suggests that controlling the "first flush" not to overtop the outlet weir is important to solve the water quality problems induced by fine sediment deposition as mentioned in Introduction.

\section{CONCLUSION}

By adjusting parameters based on field investigation results, the SS drainage module implemented in the MIKE URBAN modelling package satisfactorily reproduced the timing and peak of the first flush from a combined sewer system. However, the computation results did not express the long tail of SS concentration after the initial peak. Improving this aspect of the model is therefore being considered for further study in the future.
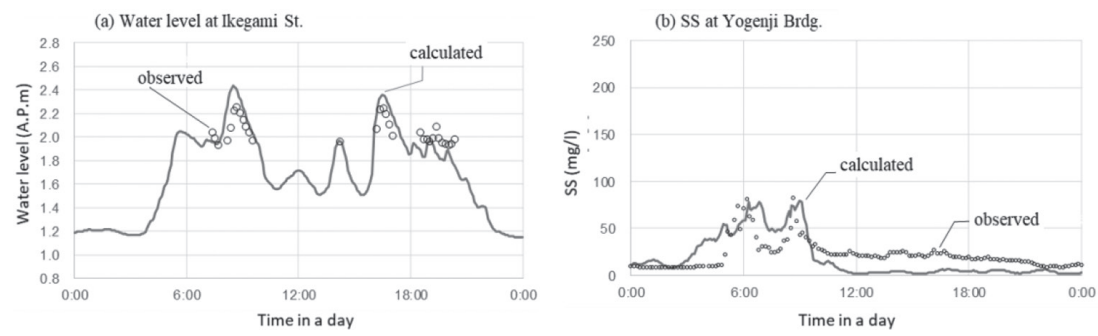

Figure 7: Water level and SS in Nomi River (Storm A: September 16-17)
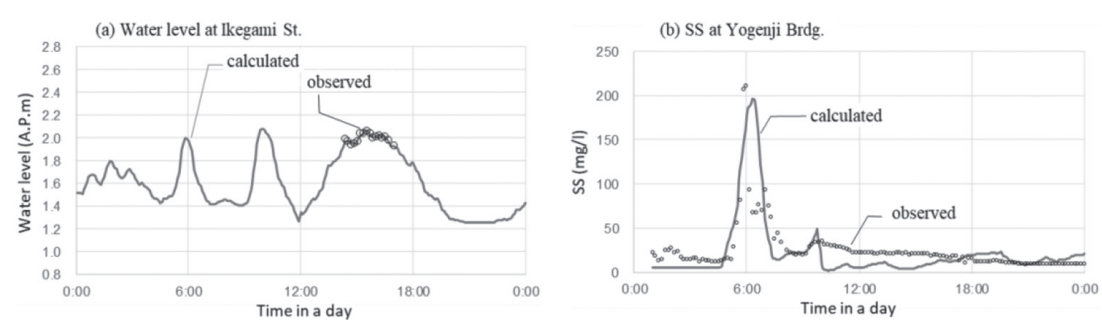

Figure 8: Water level and SS in the outlet (Storm B: September 25-26) 
As has been demonstrated previously, the discharge of high-concentration SS from the urban catchment basin occurs in the early stage of rain runoff. Accordingly, it is considered that a facility to store the first flush water before the outlets of combined sewer system would be effective to limit the amount of SS that enters river channels. The MIKE URBAN package therefore has potential as a tool for the design of such facilities.

\section{ACKNOWLEDGEMENTS}

We would like to thank Bureau of Construction, Tokyo Metropolitan Government for their support and beneficial suggestions to this study.

\section{REFERENCES}

[1] Bureau of Sewerage Tokyo Metropolitan Government, Sewerage in Tokyo2016, p. 9, 2016.

[2] Miura, S., Hotta, T., Negishi, H., Tsuruta, Y. \& Ishikawa, T., Modelling of colloidal sulfur in salinity-stratified urban streams. Proceedings of the 37th IAHR World Congress August 13-18, 2017, Kuala Lumpur, Malaysia, pp. 3442-3449, 2017.

[3] Yamazaki, M. \& Tsukui, K., Study on the formation of scum in rivers (1) Study on the origin of scum, Annual report of the Tokyo Metropolitan Research Institute for Environmental Protection 1991, pp. 171-179, 1991.

[4] Yamazaki, M. \& Tsukui, K., Study on the formation of scum in rivers (2) Results of Investigation for Sedimental Conditions in Shiratoribashi-Iidabashi Area of Kanda River. Annual report of the Tokyo Metropolitan Research Institute for Environmental Protection 1991-1992, pp. 182-184, 1991.

[5] Yamazaki, M. \& Tsukui, K., Study on the production of scum in river (3) Change in the Sediment Characteristics by a Rainfall. Annual report of the Tokyo Metropolitan Research Institute for Environmental Protection 1992, pp. 167-171, 1992.

[6] DHI, MIKE URBAN, available at http://mikepoweredbydhi.com/products/mike-urban

[7] DHI, MIKE 11, available at https://www.mikepoweredbydhi.com/products/mike-11

[8] Bureau of Construction, Tokyo Metropolitan Government, River improvement plan in the Nomi river basin, 2017.

[9] Bureau of Sewerage, Tokyo Metropolitan Government, Sewerage Mapping and Information System (SEMIS), available at http://www.gesuijoho.metro.tokyo.jp/ semiswebsystem

[10] Jonathan A.B. \& Gerald J.K., Water Resources and Environmental Depth Reference Manual for the Civil PE Exam, 2011. 